\title{
Development of amendments for rehabilitation of soils, contaminated by radionuclides, and assessment of their application efficacy
}

\author{
A.V. Konoplev ${ }^{1}$, V.E. Popov ${ }^{1}$ and L.N. Maskalchuk ${ }^{2}$ \\ ${ }^{1}$ SI "RPA Association" "Typhoon", 249038 Obninsk, Russia \\ ${ }^{2}$ SSO Joint Institute for Power and Nuclear Research - "Sosny", National Academy \\ of Sciences of Belarus, Minsk, 220109 Belarus
}

\begin{abstract}
Sapropels, hydrolyzed lignin (HL), clay-salt slimes (CSS) and phosphogypsum (PG) have been used as components to develop efficacious and ecologically safe amendments. Methods and models for forecasting effectiveness of countermeasures based on application of such amendments have been proposed. It has been found that ${ }^{137} \mathrm{Cs}$ selective sorption on organo-mineral amendments is enhanced after incubation, as compared with the calculated values on the basis of the fractions of total mass of source components and their own ability for ${ }^{137} \mathrm{Cs}$ selective sorption. The measured $\mathrm{RIP}(\mathrm{K})$ value for the mixtures of soddy-gley soil and organo-mineral amendment at $2 \%$ was $1.2-1.6$ higher than the calculated one, and at $10 \% 1.5-1.7$ times higher than the calculated.
\end{abstract}

\section{INTRODUCTION}

Application of selective to radionuclides amendments based on organic and mineral raw materials, including clay minerals, zeolites, sapropels, turf etc is very perspective agrochemical measure. Such countermeasures will result in increase of soil sorption ability to radionuclides and, therefore, decrease their availability to plant $[1,2]$.

The objective of the work was to develop efficacious and ecologically safe amendments based on natural raw materials and industrial waste and to develop methods and models for forecasting effectiveness of countermeasures as part of remediation of soils contaminated by radionuclides. Bottom sediments of freshwater lakes or sapropels surpassing by content of nutrients and microelements are of special interest among such amendments. Hydrolyzed lignin (HL), the multi tonnage trade waste, is the material like sapropel considerably increasing soil sorption ability to ${ }^{90} \mathrm{Sr}$. Clay salt slimes (CSS) have considerable stocks in Belarus and Russia and they are promising as a possible additive to amendments. The clay salt slimes are the material characterized by high dispersion and specific surface area, and considerable amount of crystalline structure defects, which increase their sorption ability in relation to ${ }^{137}$ Cs. Phosphogypsum (PG), which is a waste of phosphoric fertilizer production, could be another possible mineral addition to amendments and organomineral mixtures [3].

It is well proven now that retention of radiocaesium in soil is determined by two different processes: fixation and reversible selective sorption [4-6]. Fixation describes the permanent replacement of interlattice K- by Cs-ions. The ability of a solid to sorb radiocaesium selectively is characterised by the capacity of selective sorption sites (frayed edge sites - FES), located at the edges of micaceous clay minerals [4], or by the so called radiocaesium interception potential (RIP), which is the product of FES capacity [FES] and selectivity coefficient of radiocaesium in relation to the correspondent competitive ion $\mathrm{K}_{\mathrm{c}}(\mathrm{Cs} / \mathrm{K})$. RIP(K) can be also represented as a product of radiocaesium distribution coefficient $\mathrm{K}_{\mathrm{d}}$ and potassium concentration in solution $\left[\mathrm{K}^{+}\right]$[7].

Two kinds of $\operatorname{RIP}(K)$ can be distinguished: the total radiocaesium interception potential $\operatorname{RIP}(K)$ and the exchangeable radiocaesium interception potential $\operatorname{RIP}^{\mathrm{ex}}(\mathrm{K})$. The first one relates the total $K_{d}^{\text {tot }}$ value 
of ${ }^{137} \mathrm{Cs}$ in the soil with $\mathrm{K}^{+}$concentration in solution. The second one relates exchangeable $K_{d}^{e x}$ value of ${ }^{137} \mathrm{Cs}$ in the soil [6].

The total RIP $(\mathrm{K})$ is a valuable parameter for comparison of different materials ability for specific retention of ${ }^{137} \mathrm{Cs}$. Over time, considerable fraction of ${ }^{137} \mathrm{Cs}$ becomes unavailable for direct ionexchange due to slow fixation process, thus causing an increase in the total $\mathrm{K}_{\mathrm{d}}$ value. Being more constant with time the RIP ${ }^{e x}(K)$ can be used to predict the $\mathrm{K}_{\mathrm{d}}$ value for long term providing the $\alpha_{e x}$ and the concentration of competing ions $\left(\mathrm{K}^{+}\right.$and $\left.\mathrm{NH}_{4}^{+}\right)$in soil solution are known [6].

\section{MATERIALS AND METHODS}

\subsection{Materials}

Source materials for organo-mineral amendments (OMAs) comprised industrial wastes and natural materials from Belarus and soils from Belarus and adjacent Briansk region of Russian Federation. Table 1 contains a list of samples studied. They include two samples of clay-salt slimes, a sample of phosphogypsum, three samples of hydrolyzed lignin from Rechitsky hydrolysis plant in Belarus, sample of a silica sapropel, and soils from Belarus and Russian Federation.

\section{2 $\operatorname{RIP}(K)$ determination}

The RIP value of samples was determined according simplified procedure [8]. Approximately 0.5$1.0 \mathrm{~g}$ of soils, OMAs or soil-OMA mixtures were weighed into a $70 \mathrm{~mL}$ polycarbonate centrifuge tubes. Sample were equilibrated with $50 \mathrm{ml}$ of mixed solution of $100 \mathrm{mM}$ of $\mathrm{Ca}^{2+}$ and $0.5 \mathrm{mM}$ of $\mathrm{K}^{+}$. The liquid phase was renewed three times during 24 hours by shaking the suspension for 1 hour, centrifuging and decanting. Finally samples were equilibrated with $50 \mathrm{~mL}$ of the same solution containing $\mathrm{Ca}$ and $\mathrm{K}$, spiked with $1 \mathrm{kBq}$ of ${ }^{137} \mathrm{Cs}$. After 24 hours of end-over-end shaking and centrifuging the aqueous ${ }^{137} \mathrm{Cs}$ activities were measured using Wallac 1480 WIZARD gamma counter. RIP(K) was calculated as product of radiocaesium $K_{d}$ and potassium concentration in solution. To calculate the $\mathrm{RIP}^{\mathrm{ex}}(\mathrm{K})$ the solid phase was consecutively extracted with neutral $1 \mathrm{M}$ ammonium acetate solution [6] to determine the fraction of exchangeable ${ }^{137} \mathrm{Cs}$.

Table 1. Brief characterization of raw materials and soils.

\begin{tabular}{|l|l|}
\hline Sample Code & Brief characterization \\
\hline CSS-1-RB & Clay-salt slime (Slime storage site) \\
\hline CSS-2-RB & Clay-salt slime (Processing, desliming of sylvinite ore, Belarus) \\
\hline PG-RB & Phosphogypsum (Gomel chemical plant, Belarus) \\
\hline HL AR-RB & Hydrolyzed lignin acidic (Rechitsa, Belarus) \\
\hline HL NR-RB & Hydrolyzed lignin neutral (Rechitsa, Belarus) \\
\hline HL DR-RB & Hydrolyzed lignin «Dumping site» (Rechitsa, Belarus) \\
\hline SaprSilica R-RB & Silica sapropel (Rechitsa, Lake Chervonoe, Belarus) \\
\hline SPS-1- RB & $\begin{array}{l}\text { Sod-podzolic sandy soil with underlying loose sands, layer 5-15 cm, sampling in } \\
\text { Grabovsky forestry. Pterikovsky rayon, Gomel region, Belarus }\end{array}$ \\
\hline SPS-RF & $\begin{array}{l}\text { Soddy-podzolic soil loose sand (layer 2-3 cm, horizon Oh), sampled near v. } \\
\text { Zaborie, Krasnogorsky rayon, Bryansk region, Russian Federation. }\end{array}$ \\
\hline HGS-RF & $\begin{array}{l}\text { Humus - gley loamy sand (layer 0-5 cm, horizon À1) sampled near v. Zaborie, } \\
\text { Krasnogorsky rayon, Bryansk region, Russian Federation. }\end{array}$ \\
\hline
\end{tabular}

\subsection{Composition of binary, ternary and quaternary OMAs with CSS-2-RB}

For binary OMAs HL-AR-RB or HL-NR-RB was used as the principle organic component while CSS2-RB content was 5\%, 10\%, 15\%, 20\% and 30\%. Ternary OMA 2-1 consisted of 70\% SaprSilica R-RB, 
$20 \%$ HL NR-RB, and 10\% CSS-2-RB. In ternary OMA 2-2 amount of CSS-2-R was decreased to 5\% and SaprSilica R-RB was increased up to $75 \%$. The composition of quaternary OMA 2-3 was $70 \%$ SaprSilica R-RB, 20\% HL NR-RB, 5\% CSS-2-RB and 5\% of PG.

\subsection{Composition of ternary mixtures with CSS-1-RB}

OMA 1-1: 70\% SaprSilica R-RB, 20\% HL NR-RB, 10\% CSS-1-RB; OMA 1-2: 65\% SaprSilica R-RB, 20\% HL DR-RB, 10\% CSS-1-RB; OMA 1-3: 75\% SaprSilica R-RB, 20\% HL NR-RB, 5\% CSS1-RB; OMA 1-4: 60\% SaprSilica R-RB, 20\% HL NR-RB, 20\% CSS-1-RB; OMA 1-5: 80\% SaprSilica R-RB, 10\% HL NR-RB, 10\% CSS-1-RB.

\section{RESULTS AND DISCUSSION}

Table 2 presents key characteristics of raw materials under study. The highest ability to selectively adsorb ${ }^{137} \mathrm{Cs}$ was found in CSS the RIP(K) being 3000-6000 mM/kg. HLs and PG practically do not adsorb ${ }^{137} \mathrm{Cs}(\mathrm{RIP}(\mathrm{K})=7-32 \mathrm{mM} / \mathrm{kg})$. SaprSilica R-RB showed medium selectivity - 260-290 $\mathrm{mM} / \mathrm{kg}$. The RIP(K) values in soils ranged from 35 to $1200 \mathrm{mM} / \mathrm{kg}$ and depended partly on texture of the sample.

Table 2. Characteristics of OMAs source components and soils, abs. dry weight.

\begin{tabular}{|c|c|c|c|c|c|c|}
\hline Sample & $\mathbf{p H}_{\mathrm{K}}$ & $\mathbf{C}_{\text {org }}, \%$ & $\begin{array}{c}\text { CEC, } \\
\mathrm{cmol} / \mathrm{kg}\end{array}$ & $\begin{array}{l}\text { RIP(K), } \\
\text { mM/kg }\end{array}$ & $\begin{array}{c}\mathrm{RIP}(\mathrm{K})_{\mathrm{ex}} \\
\mathrm{mM} / \mathrm{kg}\end{array}$ & $\alpha_{\mathrm{ex}} \%$ \\
\hline CSS-1-RB & 7.7 & $1.50 \pm 0.12$ & $14.2 \pm 1.0$ & $6343 \pm 1120$ & $1066 \pm 173$ & $16.6 \pm 1.2$ \\
\hline CSS-2-RB & 7.3 & $1.96 \pm 0.29$ & $16.2 \pm 1.0$ & $3041 \pm 334$ & $434 \pm 59$ & $14.3 \pm 0.3$ \\
\hline PG-RB & 4.9 & 0.05 & . & $17.6 \pm 1.6$ & $15.5 \pm 0.6$ & $89.6 \pm 1.5$ \\
\hline HL AR-RB & 3.0 & $34.6 \pm 1.7$ & $100 \pm 3$ & $7.2 \pm 0.8$ & $3.9 \pm 0.5$ & $54.2 \pm 0.1$ \\
\hline HL N & 6.3 & 47.8 & $64.3 \pm 0.8$ & $23.3 \pm 1.8$ & $8.9 \pm 0.5$ & $41.9 \pm 1.5$ \\
\hline HL DR-RB & 2.8 & 39.8 & $72.4 \pm 2.0$ & $32.2 \pm 1.2$ & $11.4 \pm 0.3$ & $35.4 \pm 0.6$ \\
\hline SaprSilica R-RB & 4.7 & $14.3 \pm 0.6$ & $69.6 \pm 5.0$ & $288 \pm 21$ & $132 \pm 9$ & $46.0 \pm 2.1$ \\
\hline SPS-1-RB & 4.2 & $0.30 \pm 0.05$ & $8.7 \pm 1.6$ & $35.1 \pm 1.2$ & $14.0 \pm 0.9$ & $40.9 \pm 1.0$ \\
\hline SPS-RF & 3.6 & $0.62 \pm 0.03$ & $5.7 \pm 0.3$ & $440 \pm 70$ & $124 \pm 23$ & $28.1 \pm 0.8$ \\
\hline HGS-RF & 3.2 & $8.6 \pm 0.6$ & $33.9 \pm 0.4$ & $1200 \pm 70$ & $308 \pm 20$ & $25.7 \pm 0.6$ \\
\hline
\end{tabular}

The laboratory experiments performed with different organo-mineral amendments prefabricated from sapropel and industrial wastes have indicated that selective sorption of radiocaesium could be only estimated on the basis of $\operatorname{RIP}(\mathrm{K})$ values of raw materials. The difference between the expected $\mathrm{RIP}(\mathrm{K})$ values and ones measured experimentally could be as much as 2 times (Fig. 1). However, the higher experimental RIP $(\mathrm{K})$ values as compared to the predicted ones is the good news here. Alteration of containing in CSS clay minerals (probably bentonite), as a result of high $\mathrm{K}$ content and subsequent illitization of $\mathrm{K}$ bentonite is a factor generating specific binding sites for ${ }^{137} \mathrm{Cs}$. Interaction of organic matter with clay minerals could be an another factor promoting such phenomenon as shown by the experiments with binary OMAs.

However, the origin of organic matter is important as the maximum increase of ${ }^{137} \mathrm{Cs}$ selective sorption was observed with $30 \%$ of clay-salt slime added to hydrolyzed lignin and only $5 \%$ of clay-salt slime added to sapropel. The reason of such difference is not clear yet but could be connected with the nature of the organic component used. A larger contact surface area of the CSS in the mixture with organic component is hardly an explanation of such phenomenon considering that the increase in solid to solution ratio has not increased the CSS ability to adsorb ${ }^{137} \mathrm{Cs}$ selectively.

Incubation of several soils with three- and four- component OMAs also showed higher RIP(K) values than can be expected using properties of the source OMAs, soils, and their mass fractions in the mixtures. The RIP(K) values in mixtures of sod-podzolic or humus gley soils with OMAs based on CSS 


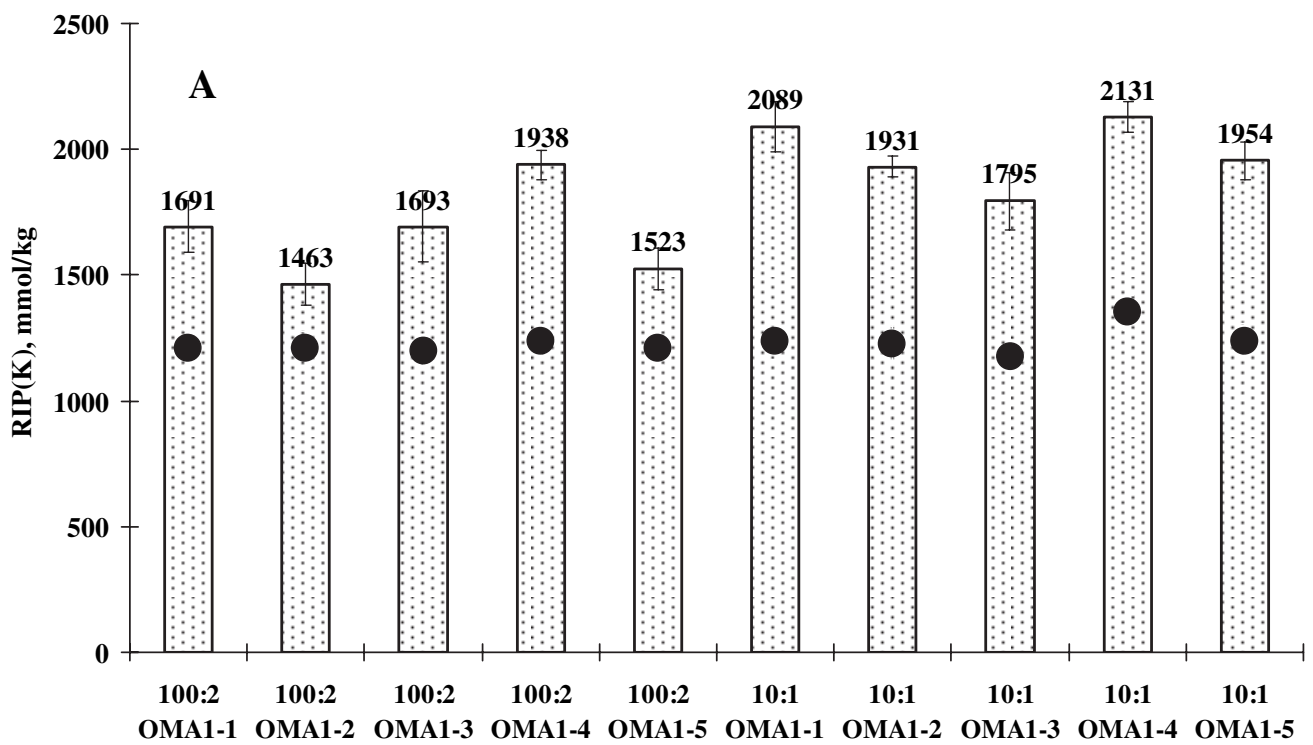

Ratio soil : OMA

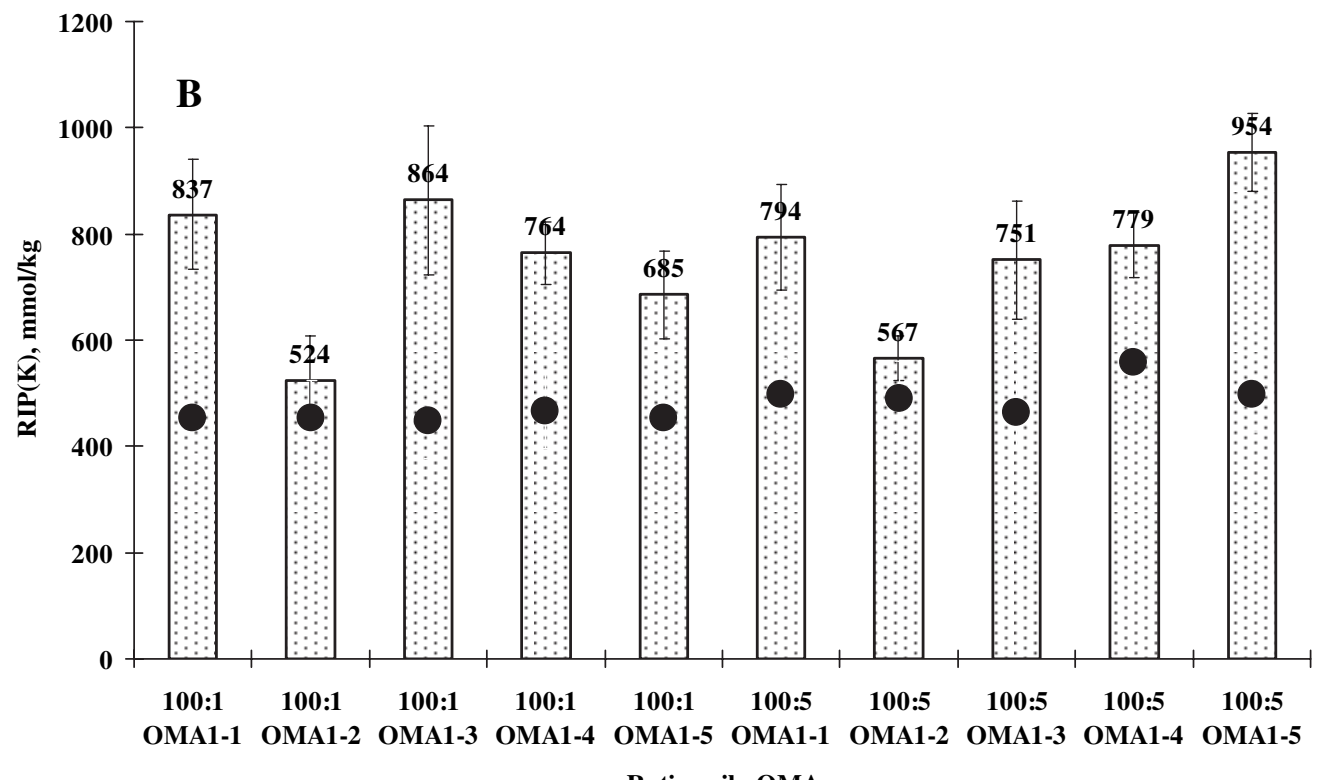

Figure 1. Experimental RIP(K) values of HGS-RF (A), and SPS-RF (B) amended with OMA-1 (columns) and $\mathrm{RIP}(\mathrm{K})$ calculated on the basis of $\mathrm{RIP}(\mathrm{K})$ values of initial components (black circles). Error bars denote the standard deviation of four replicates.

collected at a slime storage site and submitted to 8 wetting and drying cycles during 6 months were 1.2-1.9 times higher than that calculated using RIP(K) values of soils and OMAs and their mass fractions in the mixtures. With further incubation the RIP values were gradually increasing by a factor of 1.8-2.8 as compared to calculated ones (Fig. 2). Increasing number of wetting-drying cycles caused progressive increase in the RIP $(\mathrm{K})$ values of soil-OMA 2 mixtures. After 180 days of incubation the 


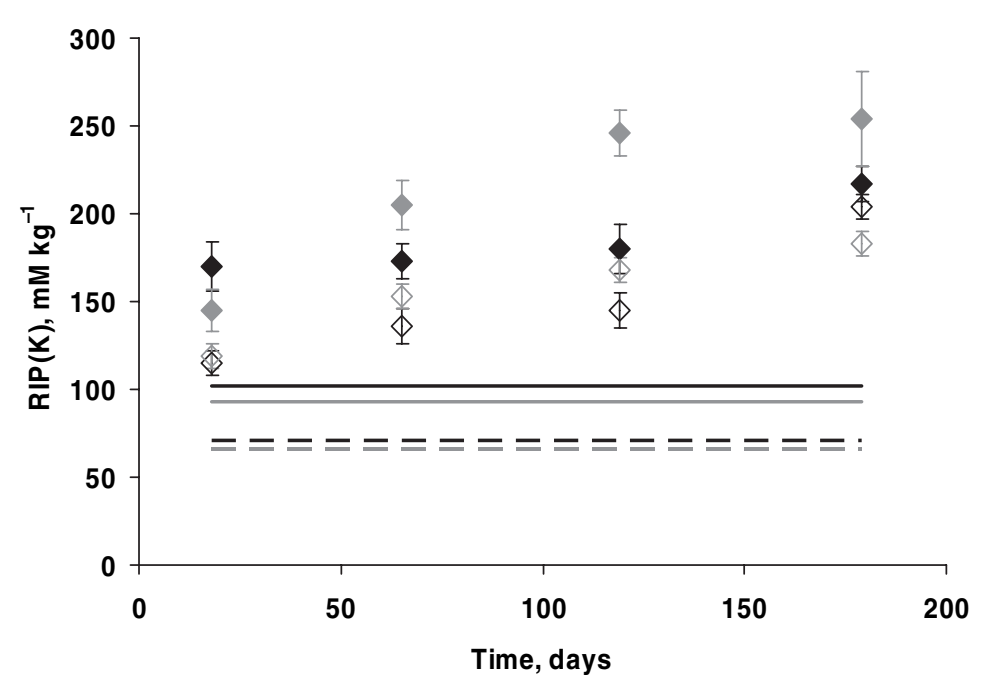

Figure 2. Experimental RIP(K) values of SPS-RB-1 amended with OMA-2 (diamonds) and RIP(K) values calculated using RIP(K) values of initial components (solid lines). Blue and red diamonds are OMA 2-1 and OMA $2-3$, respectively. Open diamonds - 5\% of OMA and solid diamonds - $10 \%$ of OMA in the soil. Error bar denote the standard deviation of two replicates. Dotted lines are calculations for the soil amended with 5\% of OMAs and solid lines - with $10 \%$ of OMAs.

$\mathrm{RIP}(\mathrm{K})$ value was increased on $25-80 \%$ for soils with addition of OMA $2-1$ and on $55-70 \%$ for soils with addition of OMA 2-2.

Enhanced ability for selective sorption of ${ }^{137} \mathrm{Cs}$ is supposed to be the combination of two processes. The first one is the interaction of organic matter with clay minerals of OMAs and soils and the second one is the influence of the OMAs drying during their prefabrication or submission to wetting and drying cycles in experiments with soils.

\section{Acknowledgments}

The work was funded by International Science and Technology Centre (ISTC) in frame of the project \#3189 "The development of composition and technology of amendment production for rehabilitation of soils contaminated by radionuclides and assessment of their application efficiency".

\section{References}

[1] E. Valcke, B. Engels and A. Cremers, Zeolites 18 (1997) 205-231.

[2] E. Valcke, A. Cremers and L. Moskaltchuk, Applied Geochemictry 13 (1998) 155-163.

[3] A.V. Konoplev and L.N. Maskalchuk, in Proceedings of International Workshop on Cleaning up sites contaminated with radioactive materials, Moscow, 2007, pp. 21-25.

[4] A. Cremers, A. Elsen, P. De Preter and A. Maes, Nature 335 (1988) 247-249.

[5] A.V. Konoplev, A.A. Bulgakov, V.E. Popov and Ts.I. Bobovnikova, Analyst 117 (1992) 1041-1047.

[6] A.V. Konoplev and I.V. Konopleva, Geochemistry International 37 (1999) 177-183.

[7] L. Sweeck, J. Wauters, E. Valcke and A. Cremers, in Transfer of Radionuclides in Natural and Semi-natural Environments, edited by G. Desmet, P. Nassimbeni and M. Belli (Elsevier Applied Sciernce, 1990), pp. 249-258.

[8] J. Wauters, A. Elsen, A. Cremers, A.V. Konoplev, A.A. Bulgakov and R.N.J. Comans, Applied Geochemistry, 11 (1996) 589-594. 
